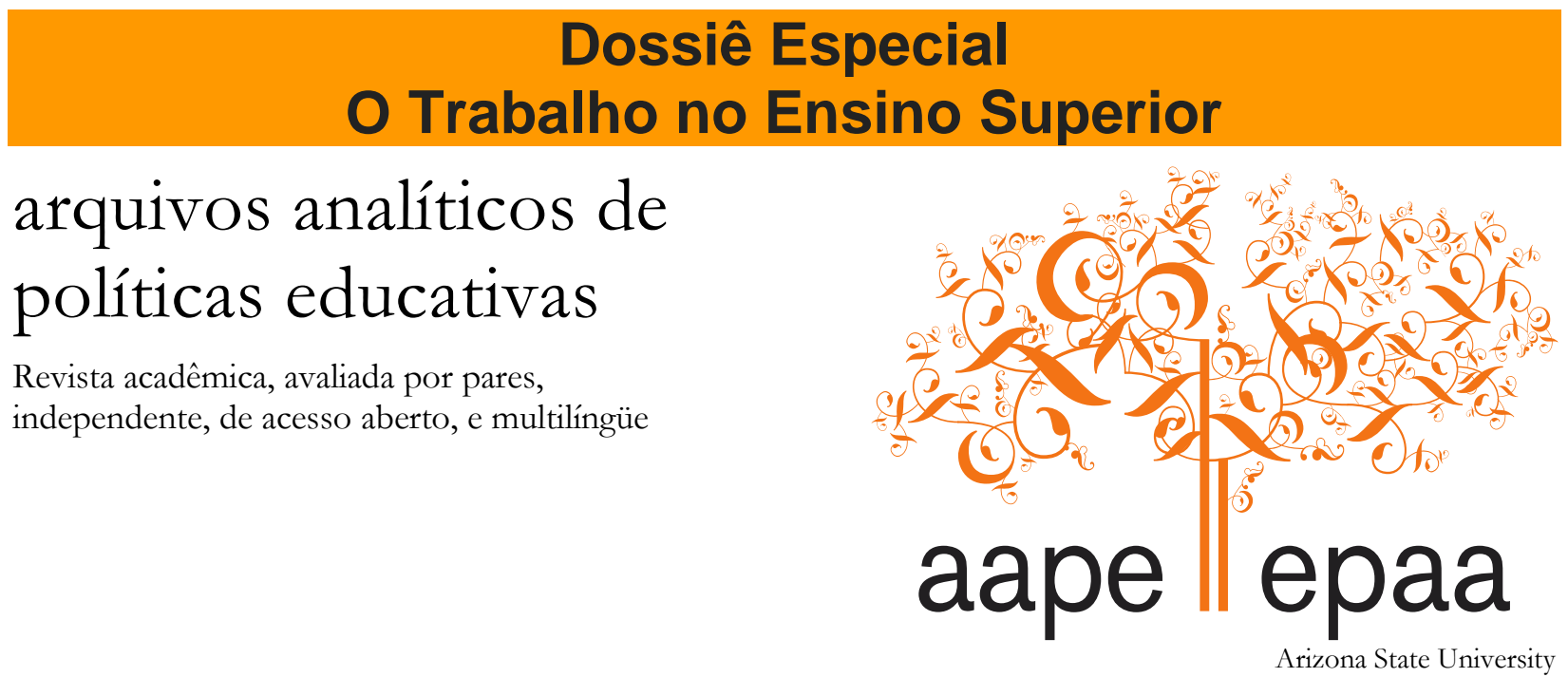

ISSN 1068-2341

\title{
A Subjetivação Capitalista enquanto Mecanismo de Precarização do Trabalho Docente na Educação Superior
}

\author{
Altair Alberto Fávero \\ \& \\ Diego Bechi \\ Universidade de Passo Fundo \\ Brasil
}

Citação: Fávero, A. A., \& Bechi, D. (2020). A subjetivação capitalista enquanto mecanismo de precarização do trabalho docente na educação superior. Arquivos Analíticos de Políticas Educativas, 28(13). https://doi.org/10.14507/epaa.28.4891 Este artigo faz parte do dossiê especial, O trabalho na educação superior, editada por Deise Mancebo, Kátia Maria Teixeira Santorum, Denise Bessa Léda, e Carla Vaz dos Santos Ribeiro.

Resumo: O modelo de subjetivação capitalista determina a generalização da concorrência como norma de conduta, intima os indivíduos a conceber a si mesmo e a comportar-se como uma empresa, ordena as relações sociais segundo o modelo de mercado e altera a lógica das políticas públicas. O presente ensaio visa compreender, a partir do referencial teórico de P. Dardot \& C. Laval (2016a, 2016b, 2010), F. Guattari (1985, 1996), G. Alves (2011, 2008), D. Mancebo (2007, 2003), dentre outros, como se constitui a subjetividade do trabalhador docente do ensino superior, diante do atual processo de expansão hegemônica da racionalidade toyotista/neoliberal, e de que forma esse processo de subjetivação capitalística tem interferido sobre as condições de trabalho e ao modo/projeto de vida dos profissionais da educação. Trata-se de um estudo exploratório quanto aos objetivos e bibliográfico quanto aos procedimentos de cunho hermenêutico-analítico. Inicialmente, o ensaio trata das transformações na estrutura político-econômica, cultural e produtiva, inerentes à 
expansão do capitalismo flexível, que deram sustentação à construção de um novo modelo de "governança" e à formação de um novo sujeito produtivo (autogovernável). Em seguida, apresenta os mecanismos e movimentos utilizados pela racionalidade toyotista/neoliberal na formação de uma subjetividade produtivista e concorrencial e suas implicações sobre os ritmos e condições de trabalho; por fim, busca compreender as metamorfoses do trabalho docente, incluindo o fenômeno relativo à intensificação e à precarização de suas condições de trabalho, decorrente do processo de subjetivação capitalista.

Palavras chave: subjetivação capitalista; educação superior; precarização; trabalho docente

\section{The capitalist subjectivation as a precarious mechanism of teaching work in higher education}

Abstract: The model of capitalist subjectivation determines the generalization of competition as a norm of conduct, intimate individuals to conceive of themselves and behave like a company, order social relations according to the market model and change the logic of public policies. The present essay aims to understand, from the theoretical reference of P. Dardot \& C. Laval (2016a, 2016b, 2010), F. Guattari (1985, 1996), G. Alves (2008, 2011), D. Mancebo (2007, 2003), among others, how the subjectivity of the teaching worker of higher education is constituted, in the face of the current hegemonic expansion process of toyotista / neoliberal rationality, and how this process of capitalist subjectivation has interfered with working conditions and the mode / life project of education professionals. It is an exploratory study regarding the objectives and bibliographical information about the procedures of hermeneutic-analytical character. Initially, the essay deals with the transformations in the political-economic, cultural and productive structure inherent to the expansion of flexible capitalism, which underpinned the construction of a new model of "governance" and the formation of a new (self-governing) productive subject. Then, it presents the mechanisms and movements used by the toyotista / neoliberal rationality in the formation of a productivist and competitive subjectivity and its implications on the rhythms and working conditions. Finally, it intents to understand the metamorphoses of the teaching work, including the phenomenon related to the intensification and precarization of its working conditions, due to the process of capitalist subjectivation.

Keywords: capitalist subjectivation; higher education; precariousness; teaching work

\section{La subjetivación capitalista como mecanismo precario del trabajo docente en la educación superior \\ Resumen: El modelo de subjetivación capitalista determina la generalización de la competencia} como norma de conducta, íntima a los individuos a concebirse a sí mismo ya comportarse como una empresa, ordena las relaciones sociales según el modelo de mercado y altera la lógica de las políticas públicas. El presente ensayo pretende comprender, a partir del referencial teórico de P. Dardot \& C. Laval (2016a, 2016b, 2010), F. Guattari (1985, 1996), G. Alves (2008, 2011), D. Mancebo (2007, 2003), entre otros, cómo se constituye la subjetividad del trabajador docente de la enseñanza superior, ante el actual proceso de expansión hegemónica de la racionalidad toyotista / neoliberal, y de qué forma ese proceso de subjetivación capitalística ha interferido sobre las condiciones de trabajo y el modo / proyecto de vida de los profesionales de la educación. Se trata de un estudio exploratorio en cuanto a los objetivos y bibliográfico en cuanto a los procedimientos de cuño hermenéutico-analítico. En primer lugar, el ensayo trata de las transformaciones en la estructura político-económica, cultural y productiva, inherentes a la expansión del capitalismo flexible, que dieron sustento a la construcción de un nuevo modelo de "gobernanza" y la formación de un nuevo sujeto productivo (autogobernable). A continuación, presenta los mecanismos y movimientos utilizados por la racionalidad toyotista / neoliberal en la formación de una subjetividad productivista 
y competitiva y sus implicaciones sobre los ritmos y condiciones de trabajo. Por fin, busca comprender las metamorfosis del trabajo docente, incluyendo el fenómeno relativo a la intensificación y precarización de sus condiciones de trabajo, derivado del proceso de subjetivación capitalista.

Palabras clave: subjetivación capitalista; educación universitaria; la precariedad; trabajo docente

\section{Introdução}

O neoliberalismo não é apenas uma ideologia, um tipo de política econômica. É um sistema normativo que ampliou a sua influência ao mundo inteiro, estendendo a

lógica do capital a todas as relações sociais e a todas as esferas da vida

(Dardot \& Laval, 2016a, p. 07)

O estudo sobre as transformações das condições de trabalho dos docentes da educação superior, no atual contexto da acumulação flexível, estrutura-se a partir do conceito de subjetividade. Por isso, o referencial teórico sobre o processo de subjetivação capitalista, constituído e apresentado por importantes pesquisadores vinculados às áreas da sociologia, filosofia e educação - a exemplo de Pierre Dardot, Christian Laval, Felix Guattari, Giovanni Alves e Deise Mancebo -, possibilita uma nova chave de leitura para compreender os mecanismos de intensificação e precarização do trabalho docente. A subjetividade (concorrencial) tornou-se um dos principais mecanismos utilizados pelo capital para aumentar a eficiência e a produtividade dos trabalhadores, bem como para submetê-los a condições precárias de trabalho. A racionalidade toyotista/neoliberal emprega técnicas de poder inéditas sobre as condutas e as subjetividades. Na acepção de Dardot \& Laval (2016a, p. 16, grifos do autor), "com o neoliberalismo o que está em jogo é nada mais nada menos que a forma de nossa existência, isto é, a forma como somos levados a nos comportar, a nos relacionar com os outros e com nós mesmos". O modelo de subjetivação capitalista determina a generalização da concorrência como norma de conduta, intima os indivíduos a conceber a si mesmo e a comportar-se como uma empresa, ordena as relações sociais segundo o modelo de mercado e altera a lógica das políticas públicas.

Em função das mudanças na estrutura e na organização do Estado nacional, alavancadas pela dinamicidade das formas de produção (toyotismo) e pela disseminação da racionalidade neoliberal, as pesquisas sobre os impactos das políticas preconizadas pela racionalidade toyotista/neoliberal sobre o trabalhador docente tem se constituído um grande desafio para as pesquisas no campo da educação. Nesse sentido, esse trabalho visa compreender, a partir do referencial teórico proposto, como se constitui a subjetividade do trabalhador docente do ensino superior, diante do atual processo de expansão hegemônica da racionalidade toyotista/neoliberal, e de que forma esse processo de subjetivação capitalística tem interferido sobre as condições de trabalho e ao modo/projeto de vida dos profissionais da educação. Para isso, o primeiro capítulo versa sobre as transformações na estrutura político-econômica, cultural e produtiva, inerentes à expansão do capitalismo flexível, que deram sustentação à construção de um novo modelo de "governança" e à formação de um novo sujeito produtivo (autogovernável). Posteriormente, são apresentados os mecanismos e movimentos utilizados pela racionalidade toyotista/neoliberal na formação de uma subjetividade produtivista e concorrencial e suas implicações sobre os ritmos e as condições de trabalho. Por fim, busca-se compreender as metamorfoses do trabalho docente, incluindo o fenômeno relativo à intensificação e à precarização de suas condições de trabalho, decorrente do processo de subjetivação capitalista. 


\section{Crise e Reestruturação do Estado Capitalista: A Ascensão do Modelo de Acumulação Flexível}

O atual processo de globalização, propalado como nova forma de organização do sistema econômico capitalista no plano mundial, tem se constituído o ponto fulcral para o entendimento da lógica predominante nas reformas estabelecidas no âmbito da educação superior e das mudanças na constituição do trabalho docente. Os ajustes educacionais de cunho neoliberal, assumidos por diversos países latino-americanos - inclusive pelo Brasil, ao longo da década de 1990 e no limiar do século XXI - refletem as profundas transformações de ordem política, econômica, social e cultural atreladas ao novo surto de universalização do capitalismo e/ou à formação da sociedade global. A globalização contemporânea, desencadeada no final do século XX, expressa um novo ciclo de expansão do capitalismo, cujas características emanam: a nova divisão transnacional do trabalho e da produção (toyotismo/flexibilização); a formação de centros decisórios extra e supranacionais; a mundialização dos mercados (fábrica global); e a disseminação e consolidação do modelo políticoeconômico neoliberal. Por conta disso, o processo de reestruturação capitalista tem provocado alterações na estrutura e organização dos Estados nacionais; produto de um receituário neoliberal que propõe a redução do intervencionismo estatal, por meio da contenção dos gastos públicos e da introdução de mecanismos de gestão inspirados na iniciativa privada. As transformacõos na estrutura produtiva e política do capitalismo, estabelecidas no bojo da sociedade global, influenciaram decisivamente a construção e a execução de políticas educacionais, provocando alterações nas condições de trabalho docente (Bechi, 2017; Castanho, 2009; Ianni, 2011).

No atual contexto de mundialização do capital, o trabalho docente se inscreve em meio a duas problemáticas centrais: a redefinição do modelo de governança do Estado e o desenvolvimento de uma nova estrutura e/ou sociabilidade produtiva. As reformas nos sistemas nacionais de educação superior, alavancadas nas últimas décadas pelos países latino-americanos, se sucederam a partir de uma nova concepção do poder e papel do Estado, gestadas nos escritórios dos organismos financeiros multilaterais (Banco Mundial, GATT, FMI, OMC, dentre outros). O processo de reprodução ampliada do capital, lançado em escala global, compreendeu as reformas e a modernização dos Estados nacionais, o controle das corporações transnacionais e das organizações financeiras multilaterais e o desenvolvimento da nova divisão internacional do trabalho e da produção. As novas experiências vinculadas à forma de organização da produção industrial e da vida social e política proporcionaram o surgimento de um regime de acumulação inteiramente novo, denominado por Harvey (2014, p. 140) de "acumulação flexível". Essa nova etapa do capitalismo mundial, associada à flexibilidade da produção, do trabalho e dos padrões de consumo, confrontou-se diretamente com a rigidez do sistema fordista-keynesiano. A derrocada do modelo econômico preconizado por Keynes, impulsionada pela crise do petróleo em meados de 1970, consubstanciou-se na redução drástica do setor estatal, especialmente mediante a privatização de diversos setores públicos, redução do tamanho do déficit fiscal e diminuição da presença do Estado na economia nacional.

A ascensão do neoliberalismo como alternativa à retomada do crescimento econômico conduziu os Estados-nação a um conturbado período de reestruturação econômica e de reajustamento social e político. O Estado, em sua configuração atual, mostrava-se incapaz de dar conta das inúmeras demandas sociais e das transformações da vida político-econômica, associadas ao processo de reestruturação da economia em escala planetária. A denominada crise do sistema fordista/keynesiano permitiu a implantação de novos mecanismos e formas de acumulação baseadas na expansão e fortalecimento da "lógica de mercado". Para os detentores do poder político e econômico em nível global, não bastava colocar freios no crescimento dos gastos públicos, era preciso mudar profundamente o modo de gestão pública de forma a viabilizar a formação de um 
governo de cunho empresarial. Para aumentar a produtividade do serviço público e agradar aos mercados, espera-se que a administração pública internalize as características de governança das empresas privadas, de forma a elevar os níveis de competição entre os serviços públicos e privados. Esse modelo de governança requer a substituição de uma administração que obedecia aos princípios do direito público, comprometida com as políticas de proteção social, por uma gestão regida pelo direito comum da concorrência (Bechi, 2013, 2017).

A reestruturação neoliberal do Estado estabeleceu um novo modelo de gestão pública inspirada sistematicamente em lógicas de concorrência e métodos de governos empregados em empresas privadas. A intenção é "reinventar o governo" pela via da construção de um novo modo de racionalização que submeta a produção dos serviços públicos à lógica de mercado, de forma a atender aos interesses oligopolistas e às recomendações dos organismos financeiros internacionais. A racionalidade capitalista em voga a partir de 1980 deu origem aos termos da "boa governança" e das "boas práticas", tornando-os uma espécie de mantra da organização governamental. O Estado eficaz, de acordo com o novo modelo de acumulação global, não se limita ao conceito de "Estado mínimo", mas vincula-se ao "Estado forte", cuja prioridade é a atividade reguladora que garanta o funcionamento e a expansão dos mercados. A governança híbrida, concentrada em torno de parcerias entre os poderes públicos e os grandes atores privados do sistema, tem gerado um profundo processo de privatização e mercantilização dos serviços públicos, incluindo o campo da educação. A lógica de acumulação flexível (toyotista/neoliberal) determinou ao Estado o papel central na difusão da norma de concorrência generalizada. A categoria política de "boa governança" perfilhou a concorrência como instrumento mais eficiente para melhorar o desempenho da ação pública (Dardot \& Laval, 2016a).

O processo de reestruturação produtiva, preconizado em favor da reestruturação econômica e do reajustamento social e político, engloba uma nova forma de organização do trabalho e da produção, amplamente dinamizada pelas inovações científicas e tecnológicas, a exemplo da automação industrial, da robótica, da informática e da microeletrônica. A fase de globalização contemporânea, alavancada pela chamada revolução tecnológica, proporcionou a substituição de uma tecnologia rígida, calcada na produção em série, de larga escala e com controle gerencial e rotinas de trabalho padronizadas, típico da grande indústria fordista, por outra mais flexível e informatizada, mediante a introdução de um novo paradigma produtivo: o toyotismo (modelo japonês). Esse modelo de produção, criado pelo engenheiro Taiichi Ohno e implementado, originalmente, na linha de produção da Toyota, deu origem a novos padrões de gestão da força de trabalho. A produção Just-in-time, caracterizada pela produção flexível e em pequenos lotes de uma variedade de tipos de produtos voltados para a demanda, exigiu a formação de um trabalhador polivalente, capaz de desenvolver múltiplas tarefas e com perfil altamente competitivo. $\mathrm{O}$ controle da força de trabalho se constitui a partir da ênfase atribuída à corresponsabilidade do trabalhador e ao sistema de pagamento pessoal associado à produtividade, substituindo o modelo de disciplinamento da mão de obra e a forma de pagamento pro rata próprio do sistema de produção em massa da era fordista. $\mathrm{Na}$ acumulação flexível, o controle deixa de ser objetivo, centrado no aspecto físico/corporal do trabalhador, e passa a ser subjetivo, por meio de estratégias de responsabilização individual e de formação da subjetividade (Alves, 2008; Harvey, 2014; Santos, 2012).

A organização horizontal da produção e do trabalho permitiu um maior engajamento laboral do trabalhador e o aumento da taxa de exploração do trabalho vivo em suas habilidades produtivas. Enquanto no fordismo as operações produtivas reduziam-se ao "aspecto físico maquinal", no toyotismo o controle do trabalho é exercido pelos próprios operários. O modelo ohnista apropria-se do savoir-faire intelectual do trabalho e eleva o envolvimento pró-ativo (corpo e mente) dos assalariados, tornando-os corresponsáveis pelo êxito da produção. O modo de produção capitalista 
não dispensa, como fez o fordismo, o espírito de operário. A apropriação da dimensão cognitiva do trabalhador permite a ampliação do número de tarefas e o incremento da produtividade do trabalho. A empresa enxuta, conforme salienta Antunes (2005, p. 36), "retransfere o savoir-faire para o trabalho, mas o faz apropriando-se crescentemente de sua dimensão intelectual, das suas capacidades cognitivas, procurando envolver mais forte e intensamente a subjetividade existente no mundo do trabalho".

A força de trabalho flexível é parte de uma ofensiva ideológica que prima pela extração de mais-valia (absoluta e relativa) por meio da redução dos custos com mão de obra e a ampliação da produtividade. A passagem do sistema capitalista fordista/keynesiano para a acumulação flexível implicou uma série de transformações políticas, sociais e culturais que abateram diretamente sobre os processos de trabalho, os padrões de consumo, as configurações geográficas e geopolíticas e as funções e práticas do Estado. As políticas de cunho neoliberal semeadas no contexto da produção flexível germinaram a competitividade e a formação do homem empresarial (autogovernável), o processo de enxugamento das políticas de proteção social e a precarização das condições de trabalho no setor público e privado. O padrão de acumulação flexível rompe com parcelização e com a repetitividade do trabalho predominantes na gestão de produção fordista/taylorista, mas mantém, em maior ou menor proporção, o apelo ao produtivismo e o trabalho alienado, traduzido pelo controle do elemento subjetivo no processo de produção. O novo modelo de acumulação capitalista torna-os submissos, por intermédio da própria razão, à lógica da competitividade e do produtivismo (Alves, 2011; Dardot \& Laval, 2016a).

A "captura" da subjetividade pela nova lógica de produção capitalista dá origem a um intenso processo de privatização e/ou empresariamento da própria existência do trabalhador, de modo a ampliar o desempenho individual e as relações de competição. A lógica da concorrência impôs uma falsa "liberdade de escolha" aos trabalhadores, induzindo-os a aceitarem as situações de mercado e a incorporem a necessidade de governar a si próprios como indivíduos responsáveis. O princípio de responsabilização do trabalhador pelo seu desempenho profissional (sucesso ou fracasso), levado a cabo pela produção flexível e pela racionalidade neoliberal, motivou o enfraquecimento dos investimentos em políticas sociais e o desmantelamento dos direitos trabalhistas. A sujeição dos trabalhadores à lei da eficácia e à lógica da concorrência tem se intensificado, sobretudo, em razão do desmantelamento e da flexibilização dos direitos do trabalhador (Antunes, 2009; Dardot \& Laval, 2016a, 2016b).

\section{A “Captura” da Subjetividade do Trabalhador pela Máquina Capitalista Neoliberal}

O modelo de acumulação capitalista contemporâneo - cujas reformas têm priorizado a flexibilização da produção e do trabalho, a redução da proteção social e a expansão da lógica de mercado - requer a formação e a execução de uma nova norma subjetiva. Esse processo de formação e adequação da subjetividade aos interesses do capital tem sido capitaneado, nas últimas décadas, pela racionalidade toyotista/neoliberal. A racionalidade toyotista/neoliberal permite criar novos desejos e modos/modelos de vida, transformar os valores culturais, estabelecer novos ritmos de trabalho e impor novos rumos às políticas públicas, interferindo diretamente sobre todas as esferas da existência humana. O processo de subjetivação visa adequar os trabalhadores (docentes) à lógica de mercado, de modo a torná-los mais competitivos e produtivos. No entanto, é válido ressaltar que essa interpretação somente é possível em função de que a subjetividade não é inata ao ser humano, mas, ao contrário, é construída por meio de sua interação com o mundo social e cultural. A subjetividade é o mundo de ideias, significados e emoções construído internamente pelo 
sujeito a partir de suas vivências e relações sociais, tornando-se fonte de suas manifestações afetivas e comportamentais (Alves, 2011; Dardot \& Laval, 2010, 2016a; Guattari, 1993).

A tese defendida neste artigo compreende a seguinte assertiva: a formação da subjetividade (produtivista e concorrencial) tornou-se um dos principais mecanismos utilizados pelo capital para aumentar a eficiência e a produtividade dos trabalhadores docentes, bem como para submetê-los a condições precárias de trabalho. Essa proposta de estudo surge, sobretudo, a partir da leitura de dois textos que exploram o princípio de subjetivação do indivíduo/trabalhador pelo novo modelo de acumulação capitalista, a saber: $A$ nova razão do mundo: ensaio sobre a sociedade neoliberal, de Pierre Dardot \& Christian Laval (2016); e Trabalho e subjetividade: o novo espírito do toyotismo na era do capitalismo manipulatório, de Giovanni Alves (2011). A primeira obra explora o processo de subjetivação do trabalhador a partir da ascensão da racionalidade neoliberal. Os partidários do neoliberalismo em âmbito global partem do pressuposto de que é necessário viabilizar a formação de um governo de cunho empresarial e eximir o Estado da responsabilidade em garantir proteção social. A racionalidade capitalista, em voga a partir da década de 1980, estabeleceu a categoria de "boa governança" inspirada sistematicamente em lógicas de concorrência e métodos de governo empregados em empresas privadas. A expansão da lógica de mercado pelo modelo de governança neoliberal compreende a consolidação do princípio da autogovernabilidade, o pleno engajamento no ambiente de trabalho e o consentimento em relação aos ideais empresariais. A construção política de uma finança global regida pelo princípio da concorrência requer a formação de um novo nexo psicofísico ou de um novo homem produtivo: o neossujeito e/ou sujeito empresarial.

A segunda obra expõe o processo de subjetivação do homem que trabalha pelo viés da reestruturação produtiva, caracterizada pela ascensão do espírito do toyotismo. Não há dúvidas de que o sistema fordista/taylorista tenha propiciado avanços na mobilidade do capital e elevado de forma significativa a produtividade do trabalho, mediante o "controle do elemento subjetivo" do trabalhador. Entretanto, o modelo de produção toyotista viabilizou um salto estratégico em direção à flexibilização da produção e das condições de trabalho, à versatilidade dos mercados e à "captura" da subjetividade humana. Em relação a essa problemática, Alves (2011, pp. 61-62) destaca que "enquanto no taylorismo fordismo 'só o gesto físico mecanizou-se inteiramente', no toyotismo, a 'mecanização' atinge corpo e mente do homem produtivo". A metodologia da produção enxuta e as novas tecnologias de base microeletrônica exigem uma nova disposição subjetiva dos operários em cooperar com a produção. O novo patamar de racionalização do trabalho corresponde à melhoria da eficiência por meio da obtenção de novos ganhos de intensidade e produtividade. Para atender a esses propósitos, o toyotismo estruturou-se a partir da desespecialização/flexibilização e do aumento da concorrência entre os assalariados. O controle do elemento subjetivo do trabalho (mente e corpo) pelo processo de reestruturação produtiva tem articulado, de maneira geral, coerção capitalista e consentimento operário.

Por meio do estudo das obras desses importantes pesquisadores, é possível compreender os mecanismos adotados pelo sistema capitalista flexível para a formação de um novo trabalhador. A racionalidade toyotista/neoliberal requer a formação de sujeitos responsáveis pelo seu desempenho individual e altamente competitivos. O neoliberalismo e o toyotismo, pilares centrais de sustentação do capitalismo flexível, não podem ser traduzidos e reduzidos, de maneira simplista, a uma doutrina político-econômica e/ou a um método de produção. Esses dois conceitos apresentam-se, em primeiro lugar, como uma racionalidade global, cujos princípios e estratégias têm fomentado um amplo e intenso processo de reterritorialização capitalista. A racionalidade toyotista/neoliberal emprega técnicas de poder inéditas sobre as condutas e as subjetividades. Na acepção de Dardot \& Laval (2016a, p. 16, grifos do autor), “com o neoliberalismo o que está em jogo é nada mais nada menos que a forma de nossa existência, isto é, a forma como somos levados a nos comportar, a nos relacionar com os outros e com nós mesmos". O modelo de subjetivação capitalista determina a 
generalização da concorrência como norma de conduta, intima os indivíduos a conceber a si mesmo e a comportar-se como uma empresa, ordena as relações sociais segundo o modelo de mercado e altera a lógica das políticas públicas (Dardot \& Laval, 2016a).

A subjetividade na contemporaneidade tornou-se a nova matéria-prima do modo de produção capitalista. As reflexões de Guattari sobre o processo de reterritorialização capitalista permitem compreender a relação existente entre capitalismo e produção da subjetividade e a forma e os interesses com que os processos de subjetivação capitalista organizam a subjetividade na atualidade. As transformações políticas e técnico-científicas, inauguradas nas últimas décadas do século XX, possibilitaram ao sistema capitalista novos mecanismos de controle do desejo, cujas engrenagens estabeleceram novos padrões de dominação e exploração. Por intermédio do controle dos desejos, é possível formar indivíduos complacentes com a categoria de "boa governança" neoliberal, além de adaptá-los à cultura do consumo e da competitividade. O novo modelo de acumulação capitalista passou a produzir desejos, formas de subjetivação, de modo a transcender a sua tradicional função de produtor de mercadorias. Com o intuito de interpretar criticamente essa nova fase de expansão do sistema capitalista, o filósofo Felix Guattari (1930-1992) criou o conceito de produção da subjetividade capitalística, acrescentando o sufixo "istico" à palavra capitalista. O conceito capitalístico permitiu analisar o controle exercido pela racionalidade capitalista em âmbito global, incluindo os países do "terceiro Mundo", do capitalismo periférico e as chamadas economias socialistas. Esse agrupamento de diferentes sociedades no mesmo núcleo investigativo se sucedeu em função de que o filósofo percebia uma semelhança na maneira de produzir e conduzir a economia e a subjetividade dos indivíduos (Guattari \& Rolnik, 1996).

A subjetividade torna-se o principal referencial de análise para compreender as metamorfoses dessa fase do capitalismo. O novo modo de produção/acumulação capitalista teria poucas chances de crescimento e expansão no cenário mundial se não houvesse o processo de captura de miniprocessos de desejo e da liberdade de singularização. O Capitalismo Mundial Integrado (CMI), responsável pela reestruturação do papel do Estado e remodelagem das forças produtivas e da vida social, é composto por mecanismos de poder que se disseminam em todos nos níveis da pirâmide social, atingindo tanto o nível dos opressores quanto o dos oprimidos. As engrenagens de produção da subjetividade capitalística são impulsionadas pelos sistemas de informação e manipulações psicológicas em grande escala, direcionadas, sobremaneira, pelos meios de comunicação de massa e redes digitais. A adequação da subjetividade aos interesses do capitalismo pós-industrial decorre de um intenso processo de produção e/ou apoderamento do desejo, realizado por meio de ações que estimulam a internalização de uma noção de cultura, denominada de cultura-mercadoria, voltada ao consumo e à lógica de mercado. Na interpretação de Guattari \& Rolnik (1996, p. 39), é "através dessa produção de subjetividade capitalística que as classes e castas que detêm o poder nas sociedades industriais tendem a assegurar um controle cada vez mais despótico sobre os sistemas de produção e de vida social"'.

O objetivo da produção da subjetividade capitalística é reduzir tudo a uma tabula rasa. O processo de reterritorialização capitalista põe em prática um intenso sobrepujamento da subjetividade capitalística em relação a toda subjetividade singularizada. O Capitalismo Mundial e Integrado (CMI) conduz uma imensa máquina produtiva de uma subjetividade serializada e nivelada em escala mundial. A laminação e homogeneização da subjetividade, impulsionada principalmente pelos meios de comunicação de massa, tendem a amassar os processos de vida social em sua riqueza e diferenciação, produzindo indivíduos iguais e processos empobrecidos. De acordo com Guattari \& Rolnik (1996, p. 42), "a ordem capitalística é projetada na realidade do mundo e na realidade psíquica. Ela incide nos esquemas de conduta, de ação, de gestos, de pensamento, de sentido, de sentimento, de afeto, etc. Ela incide nas montagens da percepção, da memorização, ela incide na modelização das instâncias intrassubjetivas". Os mecanismos de modelização subjetiva impõem o 
racismo contra tudo aquilo que não repõe ao idêntico e/ou não se enquadra ao modelo de produção e à cultura de massa, de modo a sabotar todo e qualquer movimento de criação da existência. A difusão da subjetividade capitalística dominante provocou o desabamento de todas as antigas territorialidades existenciais e dos enquadres ideológicos e a ascensão de reterritorializações fanáticas, tais como a do mito do mercado mundial (Guattari, 1985, 1993; Guattari \& Rolnik, 1996). As mudanças projetadas ao modelo de governança e ao mundo do trabalho pelo sistema toyotista/neoliberal requerem um amplo processo de subjetivação e laminação social aos moldes empresariais. Isso porque, a partir da formação e disseminação em âmbito social de uma mentalidade atrelada aos princípios neoliberais da competitividade e da livre iniciativa e avessa aos serviços públicos e às políticas de proteção social, torna-se possível o direcionamento dos comandos do poder do Estado nacional a governos inclinados às necessidades/interesses de mercado. Por meio do processo de subjetivação, conduzido, sobremaneira, com a ajuda de equipamentos coletivos de enunciação (tecnologias de informação e comunicação, redes digitais), é possível legitimar golpes, a destituição de governos, os abusos de poder e a ascensão à presidência de representantes políticos corruptos e autoritários, sob a roupagem da democracia. A laminação das subjetividades e a formação de uma identidade social de cunho empresarial favorece a implementação de reformas político-econômicas centradas na redução dos investimentos sociais, na comercialização dos serviços públicos e na flexibilização dos diretos trabalhistas.

O processo de subjetivação capitalística, operado pelo Capitalismo Mundial e Integrado (CMI), permite o aprofundamento do controle social e a consequente adequação dos trabalhadores à nova lógica de produção capitalista. Essa produção da subjetividade está profundamente marcada por vetores heterogêneos que são preeminentes sociais. Por intermédio desse processo de reterritorialização e controle social, o sistema capitalista coloca em funcionamento um conjunto de estratégias de modelização subjetiva dos trabalhadores, incluindo: os equipamentos sociais, os meios de comunicação de massa, as reformas e políticas implementadas pelos Estados nacionais, as estratégias de accountability, a cultura e/ou tecnologia da perfomatividade, dentre outros métodos psicológicos de adaptação. Por intermédio dessas estratégias de reterritorialização neoliberal, a máquina capitalista pôs em funcionamento dois importantes mecanismos com vistas a desenvolver um modelo de subjetividade produtivista e concorrencial, destinada a melhorar o desempenho dos trabalhadores e a eximir o Estado da responsabilidade em garantir proteção social, a saber: o medo/instabilidade e a responsabilização. As transformações políticas, econômicas, sociais e técnicocientíficas, inauguradas nas últimas décadas do século XX, possibilitaram ao sistema capitalista novos mecanismos de controle do desejo, cujas engrenagens estabeleceram novos padrões de dominação e exploração (Dardot \& Laval, 2016a; Guattari, 1985; Guattari \& Rolnik, 1996).

A racionalidade toyotista/neoliberal pôs em marcha dois movimentos simultâneos com vistas a atender aos interesses do capital, a saber: a diluição dos direitos trabalhistas e a generalização da concorrência. A redução da proteção social e a responsabilização individual pelos resultados obtidos são fatores que se fortalecem reciprocamente, fomentando a exploração da força de trabalho e a formação de trabalhadores submissos e complacentes às normas impostas pelo capital. Para atender aos interesses do capitalismo global, os governos nacionais determinaram o desmonte da legislação social protetora do trabalho. Além das reformas na organização da produção e a formação do trabalhador multifuncional, a reestruturação do modo capitalista de produção implica também a flexibilidade da relação salarial, dos contratos de trabalho e da regulamentação trabalhista. O enfraquecimento da proteção trabalhista e a exploração da dimensão subjetiva do trabalhador no contexto da produção flexível permite ao capital exercer pressões mais fortes de controle de trabalho. Do ponto de vista dos impactos do novo modelo de acumulação sobre as relações de trabalho, Antunes \& Praun (2015, p. 412) afirmam que "a flexibilização se expressa na diminuição drástica das fronteiras entre atividade laboral e espaço da vida privada, no desmonte da legislação 
trabalhista, nas diferentes formas de contratação da força de trabalho e em sua expressão negada, o desemprego estrutural”.

O medo do desemprego e o aumento da sensação de risco, provenientes da corrosão dos direitos trabalhistas e da redução dos investimentos sociais, submeteram os trabalhadores a um novo modelo de gestão do trabalho. O capital, aproveitando-se da instabilidade e do aumento da sensação de risco, tem apregoado ritmos mais intensos de trabalho, a fim de obter maiores níveis de produtividade e a otimização dos recursos humanos. Esse aumento da sensação de risco permitiu aos empregadores, sejam eles do setor público ou privado, exigir dos assalariados uma maior disponibilidade e comprometimento. A interiorização da norma de desempenho e o aumento de trabalhadores excluídos do processo produtivo e do mercado de trabalho permitiram que as empresas privadas e o setor público ampliassem os níveis de sujeição dos assalariados a condições de trabalho precarizadas. Segundo Alves (2011, p. 125), “por 'medo do desemprego' o trabalhador assalariado 'consente' maior nível de exploração da sua força de trabalho e renuncia os direitos sociais e trabalhistas".

Nesse contexto, a responsabilidade no âmbito do emprego tem sido transferida do Estado e do capital para os domínios do próprio sujeito. A elevação do desempenho individual e coletivo está associada a um fenômeno inerente à racionalidade toyotista/neoliberal: a individualização da responsabilidade. Isso implica a formação do "sujeito empresarial" (neossujeito), caracterizado pela capacidade de autocontrole, de engajar-se plenamente e entregar-se por completo em sua atividade profissional. A responsabilização do trabalhador, no contexto marcado pelo risco e pela ausência de proteção trabalhista, dá origem à concorrência exacerbada. Isso porque a garantia do emprego e o sucesso pessoal e/ou profissional passam a depender exclusivamente do desempenho individual em relação à equipe de trabalho - o Estado capitalista exime-se dessa responsabilidade. Essa ética da competição é vista como uma oportunidade de transferir todos os riscos e jogar os problemas de cunho social para a responsabilidade dos sujeitos. O modelo de governabilidade, centrado na redução da proteção social e na expansão da lógica de mercado, torna os indivíduos responsáveis pela própria empregabilidade e valorização de seu trabalho no mercado. As transformações produtivas, político-econômicas e culturais, inerentes ao processo de reterritorialização capitalista, tendem a jogar o peso da competição e do desempenho e/ou do fracasso profissional exclusivamente sobre o indivíduo. A individuação do desempenho leva os trabalhadores a se adaptarem ao mercado como se fossem empresas, de modo a gerenciar seus esforços para maximixar seus ganhos (Alves, 2011; Dardot \& Laval, 2016a).

$\mathrm{Na}$ atual fase de exploração capitalista, ocorre uma relação dialética entre o princípio da flexibilidade e o princípio da responsabilização. A flexibilidade em relação aos métodos e condições de trabalho, cujas mudanças têm provocado a degradação dos direitos trabalhistas, reforça a responsabilidade individual pela manutenção do emprego no mercado competitivo. Da mesma forma, a transferência de responsabilidade ao indivíduo permite ao capital intensificar os processos de flexibilização das leis trabalhistas e a implementação de métodos de gestão do trabalho que estimulem o aumento da produtividade. Responsabilidade e flexibilização se fortalecem mutuamente. Esse fortalecimento dialético, que gera intensificação e está aliado ao produtivismo, é possível a partir de um dos principais mecanismos de sujeição inerentes ao atual estágio de desenvolvimento capitalista: a "captura" da subjetividade. A máquina capitalista trabalha com a formação de indivíduos mais ativos, "protagonistas de suas escolhas" e responsáveis pelo seu próprio desenvolvimento pessoal e profissional. Segundo Dardot \& Laval (2016a, p. 328), "a racionalidade neoliberal produz o sujeito de que necessita ordenando os meios de governá-lo para que ele se conduza realmente como uma entidade em competição e que, por isso, deve maximizar seus resultados expondo-se a riscos e assumindo inteira responsabilidade por eventuais fracassos". 
O neossujeito e/ou sujeito empresarial é o homem da competição e do desempenho. A lógica de mercado e/ou concorrencial trabalha com a concepção de que o indivíduo dispõe de "livre escolha", tornando-os plenamente responsáveis pelos riscos envolvidos. O princípio da "liberdade de escolha", imposto pelo livre jogo do mercado, exige a formação de trabalhadores gestores de si mesmos. A "liberdade de escolher" está atrelada à capacidade de cálculo e de governar a si próprios como indivíduos responsáveis. O desenvolvimento da capacidade de autocontrole, baseado no princípio da liberdade e da concorrência, tornou-se um dos principais instrumentos utilizados pela máquina capitalista para disciplinar a mão de obra. Para o modelo de governabilidade neoliberal, se o indivíduo é livre para fazer escolhas, deve também responsabilizar-se pelos resultados do seu trabalho. Esse novo modelo de organização da produção e gestão do trabalho estrutura-se segundo um regime de autodisciplina que manipula as instâncias psíquicas do desejo e da culpa, transformando as necessidades objetivas em objetivos pessoais. O discurso econômico embasado na responsabilização individual permite "naturalizar" o dever pelo máximo desempenho e difundir nas massas as normas e os mecanismos necessários à consolidação da concorrência generalizada (Dardot \& Laval, 2016a).

O processo de flexibilização, inerente à nova organização do trabalho, constrói-se a partir de um movimento de reacomodação do campo sócio-subjetivo. A relação dialética entre os mecanismos de flexibilização e a formação subjetiva do trabalhador compreende o desenvolvimento de uma nova performance individual (produtivista) e o aumento da competitividade. A noção de empresa de si mesmo supõe uma integração da vida pessoal e profissional, de modo a exigir uma maior dedicação e a intensificar a exploração do tempo de vida do trabalhador para além dos murros das fábricas/instituições. Essa forma flexibilizada de gerir a produção, calcada na instabilidade/medo e na responsabilização, implicou a intensificação dos processos de trabalho, que imprimem novos ritmos à vida dos sujeitos e ao modo como se relacionam entre si. As técnicas de gestão de si estabelecem uma transformação em todos os domínios da sua existência. Além da precarização laboral (no sentido da força de trabalho enquanto mercadoria), a organização do trabalho flexível provoca a precarização existencial do homem-que-trabalha, comprometendo a saúde, a perspectiva de vida e a inserção na totalidade das relações sociais (Dardot \& Laval, 2016a, Mancebo, 2007).

O modo de produção capitalista tem formado no trabalhador uma mentalidade operária, voltada para a concorrência e a produtividade. A subjetivação capitalística tornou a concorrência uma espécie de "lei da vida" que se impõe a todos em todas as circunstâncias. As reformas políticoeconômicas e a reestruturação produtiva, aliadas ao modelo de produção capitalista pós-industrial, partiram do pressuposto de que a fonte da eficácia está no indivíduo. A máquina capitalista opera com o intuito de produzir um "eu produtivo", que exige sempre mais de si mesmo e cuja autoestima está vinculada à busca por melhores desempenhos individuais. As engrenagens da máquina capitalista trabalham para remodelar a subjetividade no trabalho e na vida privada de acordo com o princípio da concorrência. A "captura" da subjetividade do trabalhador, sobretudo a partir do aprofundamento da instabilidade e da responsabilização (accountability), amplia as forma de precarização do trabalho, pois adentra os diferentes domínios da vida. Os mecanismos de contrapartida salarial (avaliação contábil) e os novos modos de organização do trabalho (toyotismo/flexibilização) sedimentaram os consentimentos espúrios dos trabalhadores em relação à lógica produtivista e concorrencial. A precarização contratual e a individuação dos desempenhos e gratificações permitiram que a concorrência fosse internalizada pelos assalariados como um tipo normal de relação no mercado de trabalho.

\section{As Metamorfoses do Trabalho Docente no Contexto Neoliberal}


As leituras que compreendem a relação, de caráter dialético, entre capitalismo, subjetividade e trabalho, embora não atentas ao campo da educação, auxiliam na construção de uma nova forma de pensar e interpretar as metarmofoses do trabalho docente. A tese de que a subjetivação mercantilizada e empresarial deteriora as condições de vida e de trabalho dos profissionais da educação é potencializada pelas pesquisas realizadas por Mancebo $(2003,2007)$. De acordo com a pesquisadora (2007, pp. 76-77), as características próprias ao trabalho flexível têm se feito presente e com grande intensidade nas instituições universitárias e no trabalho do professor, impondo uma nova lógica às rotinas acadêmicas. A ascensão da racionalidade neoliberal e os novos processos de trabalho forjam a subjetividade docente e alteram a dinâmica da produção universitária. Por isso, a análise das metarmofoses do trabalho docente pelo viés da subjetividade permite resgatar e compreender os mecanismos de sujeição adotados pelo modo de produção capitalista para elevar a produtividade acadêmica e o contingente de profissionais subcontratados, a saber: a

responsabilização, a flexibilidade e a concorrência. Esses mecanismos estão atrelados à constituição da subjetividade docente e sua submissão aos interesses do mercado. Como consequência desse processo de subjetivação, destaca-se a destruição dos direitos trabalhistas e a subsunção dos profissionais da educação aos ditames da lógica produtivista/mercantilista.

As reformas político-econômicas neoliberais e a reestruturação produtiva (produção flexível) propalada pelo novo estágio de desenvolvimento e universalização do capitalismo têm estimulado a mercantilização da educação superior e a subsunção da subjetividade docente à lógica perversa do capital. A "captura" da subjetividade dos docentes das IES decorre, sobremaneira, da elaboração e implementação de políticas que primam pela expansão da lógica de mercado no campo educacional. A instrumentalização das políticas educacionais para fins mercadológicos e o fenômeno relativo à precarização/intensificação do trabalho docente nas instituições de ensino superior estão associados à formação de uma nova subjetividade (concorrencial e produtivista) condizente com as transformações político-econômicas subjacentes à nova lógica de acumulação capitalista (Bechi, 2011; Fávero \& Bechi, 2017).

A "captura" da subjetividade pela racionalidade toyotista/neoliberal ataca os docentes em seu íntimo, exercendo um forte controle que o coloca a serviço do capital. O processo de subjetivação docente está, em essência, aliado a um conjunto de medidas baseadas na lógica de mercado, incluindo: redefinição da carreira docente a partir da flexibilização das relações de trabalho; salário baseado no mérito e gratificação por desempenho; avaliação baseado em regras objetivas; mecanismos de acreditação e definição de normas a nível nacional e internacional. No contexto das reformas neoliberais, o profissional da educação deve oferecer sua força de trabalho em troca de um salário baseado em sua "produtividade" e a sujeitar-se às diferentes formas de (sub) contratação. Para manter-se no mercado, o docente é forçado a se adaptar às exigências do modelo de trabalho flexível e à desregulamentação das relações trabalhistas. As reformas da educação superior, preconizadas pela racionalidade toyotista/neoliberal, proporcionaram a (re) articulação das funções, das responsabilidades, das expectativas e das condições de trabalho docente. As mudanças direcionadas ao trabalho docente estiveram articuladas à lógica econômica fundada "na transferência de responsabilidades para os indivíduos; na desarticulação da categoria dos docentes; no estabelecimento de aprendizagens necessárias ao trabalho flexível; na ênfase no desempenho, na eficiência e na produtividade; na indução à competitividade e na tendência à formação aligeirada" (Carvalho \& Wonsik, 2015, p. 387).

O projeto societário reclamado pelo capital no contexto atual conduziu a um movimento de dilatação das atividades do professor a partir da desregulação e da redefinição das suas atividades laborais. As reformas imanentes ao novo modelo de governança do aparelho Estado, inspiradas no toyotismo e no neoliberalismo, provocaram a reestruturação das funções, das responsabilidades, das 
expectativas, das formas de emprego e das condições de trabalho docente. Essas transformações estiveram relacionadas a uma nova percepção sobre a qualidade da educação, projetada com base em princípios quantitativos. A qualidade da educação, segundo a perspectiva economicista-neoliberal, está atrelada ao desempenho e à eficiência profissional dos trabalhadores docentes. Nessa perspectiva, não há como elevar o desempenho educacional se não forem implementadas mudanças na configuração laboral dos profissionais da educação. As reformas educacionais devem primar pela profissionalização do trabalho docente, com forte ênfase no desenvolvimento de uma nova performance individual e na valorização de sua produtividade. Essa necessidade de adaptar o trabalho docente às necessidades impostas pela lógica de mercado é justificada a partir da mensuração e publicização dos resultados das avaliações de desempenho. Os métodos avaliativos, de caráter estritamente quantitativo, têm servido, sobremaneira, para intensificar o empenho dos docentes na produção de resultados, emergindo-os à lógica produtivista (Brito, Prado \& Nunes, 2016; Carvalho \& Wonsik, 2015).

A perspectiva economicista-neoliberal compreende os trabalhadores da educação como agentes responsáveis pelas mudanças no contexto das reformas educacionais. Os neoliberais acreditam que o desenvolvimento econômico, político, social, cultural e individual dependem fundamentalmente da adequação dos trabalhadores à nova morfologia do trabalho. Seguindo essa lógica, os trabalhadores da educação são primordiais à melhoria do desempenho dos alunos, da escola e do sistema. Sendo assim, essa perspectiva possui como característica discursiva a culpabilidade outorgada aos docentes pelo fracasso das reformas (Feldfeber, 2007; Oliveira, 2005; Tello, 2011). Nessa mesma linha analítica, Alejandra Shulmeyer (2002, apud Tello, 2011, p. 155) destaca que "atualmente se observa um certo consenso quando a ideia de que o fracasso ou o sucesso de todo o sistema educacional, na porcentagem da variância explicada pela escola, depende fundamentalmente, ou ao menos em grande medida, da qualidade do desempenho dos seus docentes". Por isso, os neoliberais acreditam que os índices da educação irão evoluir somente quando o trabalho docente estiver engajado ao princípio da accountability. Para isso, torna-se necessário estabelecer políticas que estimulem o crescimento profissional e a melhoria da performance docente. Isso requer a aplicação de incentivos financeiros e a intensificação da competitividade por meio da avaliação e publicização dos resultados individuais e coletivos. Os salários, a promoção, o cargo e a retenção dos professores devem estar atrelados aos sinais de mercado e baseados no desempenho (Feldfeber, 2007).

O docente é considerado o ator principal no cenário de buscas pelo melhoramento da qualidade educativa, pois é o nexo entre as perspectivas/necessidades educacionais e o processo de aprendizagem dos alunos. O fracasso da educação nos países da América Latina está relacionado ao atraso e/ou à falta de um sistema avaliativo que estimule os docentes a serem mais eficazes e comprometidos com os resultados do seu trabalho. A produtividade docente deve estar sujeita a um modelo de avaliação efetivo, de maneira que os melhores profissionais possam ser recompensados, por meio de gratificações e bônus salarial, e os que apresentarem baixo rendimento sejam direcionados a processos de reciclagem ou demitidos (Feldfeber, 2007; Tello, 2011). Nessa direção, Mello (2005, apud Tello, 2011, p. 156) acredita que "o mais importante é criar uma cultura de avaliação do desempenho docente que legitime o uso dos resultados para estabelecer políticas de formação, recrutamento, contratação visando à melhoria da qualidade e à promoção da igualdade na educação". A constante ameaça de perder o emprego no caso de que seja comprovado seu baixo desempenho e os incentivos financeiros e profissionais aos que apresentarem melhores resultados, intensificaria a competitividade e estimularia os docentes a melhorar sua performance.

A valorização da profissionalização docente, a fim de aumentar a eficácia laboral e a produtividade individual, está articulada à flexibilização atribuída ao mundo do trabalho pela racionalidade toyotista/neoliberal. A implementação de reformas que expõem os trabalhadores 
docentes ao medo do desemprego e a responsabilização individual em relação aos resultados obtidos pelos sistemas avaliativos correspondem às estratégias de "captura" da subjetividade inerente à lógica de acumulação flexível. O estímulo à competitividade e ao desempenho individual, para obtenção de melhores salários e condições de trabalho, assemelha a categoria docente às demais categorias de trabalhadores, tornando-a uma categoria de trabalho facilmente explorável e relativamente impotente. Essas transformações nas condições e relações de trabalho docente ocorrem na medida em que os setores produtivos e a lógica de mercado avançam sobre o trabalho material e imaterial para conseguir unir produtividade, excelência e redução do tempo de execução das atividades. As consequências de todo esse processo são múltiplas aos docentes que atuam no setor público e privado, destacando-se: a precarização do trabalho, a flexibilização das tarefas e uma nova relação que se estabelece com o tempo de trabalho (Carvalho \& Wonsik, 2015; Mancebo, 2007).

No contexto da acumulação flexível, a proletarização é apresentada sob a roupagem da profissionalização. A remuneração por desempenho e a flexibilização do trabalho, expressados como ações relevantes à carreira docente, têm, na realidade, intensificado o processo de proletarização dos profissionais da educação. O surgimento do precariado docente decorre, indubitavelmente, da construção de políticas articuladas às metamorfoses do mundo do trabalho, impulsionadas, sobremaneira, pela reestruturação produtiva e pela flexibilização das leis trabalhistas. No contexto neoliberal, "o professor da educação superior tem assistido à perda gradual do reconhecimento de sua profissão, que vem deixando de ser atrativa em função dos baixos salários, das condições inadequadas de trabalho, da inexistência de um plano de carreira que, de fato, a valorize" (Maués \& Souza, 2016, p. 81).

A proliferação da lógica de mercado no campo da educação superior aproxima, a passos largos, os profissionais da educação ao contingente de trabalhadores que vivenciam as condições mais desprovidas de direitos e a instabilidade cotidiana, dada pelo trabalho part time, temporário e subcontratado. Os docentes não estão alheios às transformações nas condições objetivas de trabalho que atinge a classe-que-vive-do-trabalho. As reformas no sistema político, social, econômico e cultural, impulsionadas pela ascensão do espírito toyotista/neoliberal e pelo desenvolvimento das tecnologias digitais, condicionaram o trabalho imaterial, incluindo o trabalho docente, aos ditames da racionalidade financeira. Os docentes estão cada vez mais a mercê de condições aviltantes de trabalho devido à retração do Estado no que tange ao financiamento público da educação e ao intenso processo de mercantilização e empresariamento da educação superior. As instituições educacionais encontram na flexibilização das leis trabalhistas formas de reduzir e otimizar os recursos investidos e, assim, aumentar a eficiência administrativa e elevar a competitividade institucional no "quase-mercado" educacional. Na chamada sociedade pós-moderna, os profissionais da educação estão sendo plenamente incorporados à lógica economicista e produtivista. Em razão disso, na acumulação flexível, a figura do professor efetivo - concursado, estável, estatutário e em regime de dedicação exclusiva - tende a compartilhar, de forma cada vez mais intensa, os objetivos, as funções e o ambiente universitário com profissionais contratados em regime temporário e com vínculos trabalhistas precarizados. O precariado, de maneira geral, compreende formas de trabalho de natureza frágil, instável, casual, informal, parcial, sendo explorado dentro e fora do local de trabalho (Antunes, 2018; Brito, Prado \& Nunes, 2017; Maués \& Souza, 2016).

No Brasil, as iniciativas neoliberais de redução dos investimentos públicos na área na educação e o profundo empresariamento da educação superior possibilitaram a ampliação de contratações de professores por tempo determinado, organizados sobre o regime da Consolidação das Leis do Trabalho (CLT), e de (sub) contratações precárias, por vezes firmadas às margens da lei, por ocultar os direitos trabalhistas dos docentes. As empresas educacionais instaladas no Brasil têm apostado na demissão em massa de docentes e na posterior (re) contratação com base na nova legislação trabalhista (Lei 13.467/2017). A precarização das condições de trabalho docente atinge, 
diretamente, e com maior intensidade, os professores temporários e/ou contratados por hora de trabalho (subcontratados). Esses profissionais não têm estabilidade, recebem salários mais baixos, pois não estão inclusos em planos de carreira, não têm direito a gratificações e, em muitos casos, não recebem décimo terceiro, férias, dentre outros direitos que são garantidos aos professores efetivos. Com relação às formas de contratação, há professores-horistas exercendo suas funções sem carteira de trabalho assinada ou sem qualquer proteção legal. A instabilidade quanto à conquista/manutenção do emprego e os baixos salários pressionam os docentes a ampliar a carga horária via contratos provisórios, enfraquecem o vínculo com as IES e estimulam as "carreiras nômades". O aumento da flexibilidade fomenta a individualização do trabalho em termos técnicos e sociais, tornando-se responsável por desatar laços de solidariedade e de seguridade (Brito, Prado \& Nunes, 2017; Mancebo, 2007; Maués \& Souza, 2016; Miranda, 2005).

A proliferação de subcontratação de professores nas IES públicas e privadas advém da necessidade, imposta pela lógica de produção capitalista, de diminuir os custos de produção e intensificar o controle sobre a sua subjetividade. A formação subjetiva é uma das principais estratégias adotadas pelo capitalismo flexível para gerir o tempo produtivo do trabalhador. A ampliação da produtividade laboral acontece por meio da internalização do espírito competitivo e empreendedor, estimulado pelos processos de responsabilização (accountability) e flexibilização. A instabilidade proveniente da flexibilização das condições de trabalho e a responsabilização dos trabalhadores pelos resultados individuais são elementos que sustentam a construção de uma nova subjetividade docente. No contexto da educação superior, o docente é condicionado, de forma subjetiva, a estabelecer uma nova relação com o tempo, retratada na aceleração da produção e ampliação da jornada de trabalho. A subjetivação docente constitui uma das principais estratégias consubstanciadas pelo capitalismo flexível para elevar a (auto)intensificação do trabalho. A concorrência e o produtivismo são assumidos pelos trabalhadores como um projeto de vida pessoal. Isso ocorre porque o projeto toyotista/neoliberal sustenta sua estrutura política, econômica, cultural e produtiva nos princípios da autonomia e da liberdade. A visão economicista pressupõe que todos os trabalhadores possuem condições para conquistar o progresso profissional, basta aliar performance e flexibilidade (Brito, Prado \& Nunes, 2017; Campos, 2005).

No contexto neoliberal, o trabalhador docente torna-se responsável pelo seu desempenho, renda e futuro profissional. Esse processo de responsabilização, aliado à instabilidade profissional, tem provocado a subsunção da subjetividade docente aos interesses do mercado. A internalização da lógica de mercado pelas políticas educacionais, preconizadas pelo modelo de acumulação flexível, tornaram as IES "reféns do capital e os pesquisadores a mais nova categoria de trabalhadores explorados, sem necessidade de fábricas nem de esteiras mecânicas nem de cartões de ponto" (Machado \& Bianchetti, 2011, p. 249). Em razão disso, os professores da educação superior se encontram em uma situação complexa de trabalho, em um contexto marcado pelo constante aumento do nível das demandas laborais e pelo prolongamento do tempo de trabalho. Eles são obrigados a desempenhar múltiplas e variadas atividades que, por sua vez, vão além das funções docentes e, na maioria das vezes, são desempenhadas para além dos muros das IES. Além das atividades de sala de aula, os profissionais docentes desenvolvem atividades de investigação, extensão e gestão e vinculadas à sua formação, nas quais se somam atividades como o preenchimento de inúmeros relatórios, formulários, emissão de pareceres, captação de recursos extraorçamentários, dentre outras. A dinâmica produtivista importa para o interior das IES a sociedade da urgência, pois compreende leituras apressadas do último lançamento, o imediatismo das pesquisas, o aligeiramento dos cursos e a formação de mais alunos em menos tempo (Mancebo, 2007; Walker, 2016).

A multiplicidade e o aligeiramento de tarefas deu origem a um processo de dilatação das atividades do professor e a consequente intensificação e precarização das condições de trabalho. O 
novo modelo de produção, preconizado pelas reformas educacionais e pelo mercado educacional, força o incremento de tarefas, o estabelecimento de horários atípicos, a aceleração no desenvolvimento das atividades. Ao assumir várias funções e responsabilidades, o tempo produtivo do docente ultrapassa o tempo de trabalho prescrito. Por conseguinte, o tempo de trabalho despendido para a realização das múltiplas atividades demandadas, além de acelerado, não é delimitado. A produtividade invade o tempo do ócio, do lazer, do descanso, das atividades em família. O trabalho torna-se exclusividade no contexto marcado pela flexibilidade e polivalência. $\mathrm{O}$ controle do tempo de trabalho deixa de existir em razão do controle da produtividade, imposto pelos métodos avaliativos quantitativos e pela intensificação da concorrência. Assim sendo, a lógica da produtividade insere-se na vida profissional e acadêmica, trazendo vários prejuízos às relações interpessoais e à subjetividade dos profissionais da educação (Brito, Prado \& Nunes, 2017; Mancebo, 2007; Walker, 2016).

O cenário de expropriação dos direitos dos trabalhadores e a submissão da subjetividade aos interesses do capital impactam diretamente sobre a vida pessoal e profissional do professor. A nova lógica de acumulação capitalista, caracterizada pelo enxugamento orçamentário e pela flexibilização da produção e do trabalho, "intensifica o regime de trabalho, aumenta o sofrimento subjetivo, neutraliza a mobilização coletiva e aprofunda o individualismo, atingindo, obviamente, não somente os trabalhadores precários, mas carreando grandes consequências para a vivência e a conduta de todos aqueles que trabalham nas IES" (Mancebo, 2007, p. 77). A abdicação do tempo de descanso, de lazer e de hábitos saudáveis como a prática de atividades físicas, em prol da produção acadêmica, pode comprometer seriamente a saúde dos docentes. O contexto de expropriação de direitos e de intensificação do trabalho docente reduz os sentimentos de prazer e gera estresse e insatisfação com a profissão. A sobrecarga de trabalho e a insegurança financeira produz uma experiência de trabalho marcada pelo sofrimento, que se expressa de diferentes formas: cansaço, desinteresse, aborrecimento, angústia, frustração, sensação de inutilidade. Esses sentimentos têm provocado o adoecimento físico e/ou psíquico dos trabalhadores docentes (Walker, 2016, p. 116).

\section{Considerações Finais}

As reformas político-econômicas e as novas formas de gestão da produção e do trabalho cujas ações têm gerado flexibilização/precarização contratual -, o medo do desemprego, a avaliação de desempenhos e a responsabilização individual (accountability), constituem-se poderosas alavancas de concorrência e definem novos modos de subjetivação. A expansão do espírito toyotista e da racionalidade neoliberal, cujas características favoreceram a consecução da lógica de mercado, coloca o trabalho imaterial e o trabalho improdutivo no centro dos interesses produtivos e econômicos. A racionalidade toyotista/neoliberal estimulou o processo de mercantilização e privatização da educação superior, com sérias implicações sobre a subjetividade e o trabalho docente.

No contexto da acumulação flexível, os trabalhadores docentes vêm sendo pressionados a aumentar quantitativamente a produção de modo a atender às metas de pontuações definidas pelos órgãos de fomento à pesquisa, aos indicadores de avaliação institucional e às políticas de diversificação e racionalização dos recursos financeiros. As políticas da educação superior têm provocado alterações substantivas nas condições de trabalho docente, dentre as quais é possível destacar: a flexibilização contratual das relações de trabalho por meio da incorporação e/ou da proliferação de (sub) contratações temporárias de professores segundo as novas leis trabalhistas; a redução das remunerações, sem perspectivas de recuperação de perdas salariais; desempenho acadêmico baseado na lógica produtivista; intensificação do regime de trabalho em função da sobrecarga de aulas/turmas, das exigências por maior produtividade docente e do respectivo 
aumento da carga horária real e extraclasse; flexibilização do trabalho decorrente do incremento e/ou da diversificação de tarefas a serem cumpridas; e a constante submissão do professor a diferentes sistemas avaliativos. O constante clima de ameaça e instabilidade resultante do enxugamento ou da otimização da máquina produtiva e das estratégias de controle da produção tem gerado o acirramento da competitividade, o aumento do potencial de conflitos psicológicos e interpessoais e a responsabilização dos docentes em relação ao seu desempenho individual. Esse modelo de governança, baseado, sobremaneira, na racionalização financeira e no aumento da produtividade, tem intensificado o processo de proletarização docente (Santos, 2012).

\section{Agradecimentos}

Esse é o formato de como um aviso de agradecimento deve aparecer. Reconhecimentos e notas de agradecimento a indivíduos específicos podem às vezes ser formalmente colocados entre o final do texto e as referências. Agradecimentos não incluem o reconhecimento de agências de financiamento e/ou fontes, notas sobre traduções ou versões anteriores do artigo. Estes devem ser inseridos em notas de rodapé ou numa frase no parágrafo introdutório do artigo.

\section{Referências}

Alves, G. (2008). O espírito do toyotismo - reestruturação produtiva e "captura" da subjetividade do trabalho no capitalismo global. Confluências - Revista Interdisciplinar de Sociologia e Direito, Niterói, 10(1) 97-121.

Alves, G. (2011) Trabalho e subjetividade: O espírito do toyotismo na era do capitalismo manipulatório. São Paulo: Boitempo.

Antunes, R. (2005). O caracol e sua concha. Ensaios sobre a morfologia do trabalho. São Paulo: Boitempo.

Antunes, R. (2009). Os sentidos do trabalho: Ensaios sobre a afirmação e a negação do trabalho. São Paulo: Boitempo.

Antunes, R. (2011). Os modos de ser da informalidade: Rumo a uma nova era da precarização estrutural do trabalho. Serviço. Social \& Sociedade, São Paulo, (107), 405-419, jul./set.

Antunes, R. (2018) O privilégio da servidão: O novo proletariado de serviços na era digital. São Paulo: Boitempo.

Antunes, R.; Praun, L (2015). A sociedade dos adoecimentos no trabalho. Serviço. Social \& Sociedade, São Paulo, (123), 407-427, jul./set.

Bechi, D. (2011). Mercantilização do ensino superior: Os desafios da universidade diante do atual cenário educacional. Acta Scientiarum. Education, 33, 139-147.

Bechi, D. (2017). As reformas da educação superior e as metamorfoses do trabalho docente na economia capitalista flexível. Revista Internacional de Educação Superior, Campinas, SP, 3(1), 203-223, jan./abr.

Brito, R. dos S., Prado, J. R., \& Nunes, C. P. (2017). As condições de trabalho docente e o pósestado de bem-estar social. Revista Tempos e Espaços em Educação, São Cristóvão, Sergipe, Brasil, v. 10, n. 23, p. 165-174, set./dez.

Campos, V. S. (2005). Flexibilización laboral de la docencia universitaria y la gest(ac)íon de la Universidad sin órganos: Un análisis desde la subjetividad laboral del docente en condiciones de precariedad. In: P. Gentil, P. \& B. Levy (Orgs.). Espacio público y privatización del conocimiento: Estudios sobre políticas universitarias en América Latina. Buenos Aires: CLACSO. 
Carvalho, E. J., \& Wonsik, E. (2015). Políticas educacionais atuais: Valorização ou precarização do trabalho docente. Revista Contrapontos - Eletrônica, Itajaí, v. 15 - n. 3, p. 373-393, set-dez.

Castanho, S. E. M. (2009). Globalização, redefinição do Estado nacional e seus impactos. In: J. C. Lombardi (Org.). Globalização, pós-modernidade e educação (pp. 13 - 35). Campinas, SP: Autores Associados.

Dardot, P., \& Laval, C. (2016a). A nova razão do mundo: Ensaios sobre a sociedade neoliberal. São Paulo: Boitempo.

Dardot, P., \& Laval, C. (2016b). Neoliberalismo e subjetivação capitalista. O Olho da História: Revista de Teoria, Cultura, Cinema e Sociedades, Salvador, (22), abr.

Dardot, P., \& Laval, C. (20110). Néolibéralisme et subjectivation capitaliste. Cités/CAIRN.INFO, (41), 35-50.

Fávero, A. A., \& Bechi, D. (2017). O financiamento da educação superior no limiar do século XXI: O caminho da mercantilização da educação. Revista Internacional de Educação Superior, 3, 90-113.

Feldfeber, M. (2007). La regulación de la formación y el trabajo docente: Un análisis crítico de la "Agenda educativa" en América Latina. Educação e Sociedade, Campinas, 28(99), 444-465, maio/ago.

Guattari, F. (1985). Revolução molecular: Pulsações políticas do desejo. (Trad. S. Rolnik). São Paulo: Brasiliense.

Guattari, F. \& Rolink, S. (1996). Micropolítica: Cartografias do desejo. Petrópolis: Vozes.

Guattari, F. (1993). Guattari na PUC (Entrevista). Cadernos de subjetividade, São Paulo, PUC, 1(1), 9 28 , mar / ago.

Harvey, D. (2014). Condição pós-moderna. São Paulo, SP: Loyola.

Ianni, O. (2011). A era do globalismo. Rio de Janeiro: Civilização Brasileira.

Machado, A. Ma., \& Bianchetti, L. (2011). (Des)fetichização do produtivismo acadêmico: Desafios para o trabalhador-pesquisador. RAE, São Paulo, 51(3), maio/ jun., 244-254.

Mancebo, D. (2007). Trabalho docente: Subjetividade, sobreimplicação e prazer. Psicologia: Reflexão e Crítica, Porto Alegre, 20(1), 74- 80.

Mancebo, D., \& Franco, Ma. E. (2003). Trabalho docente: Uma análise das práticas intelectuais em tempos de globalização. In: D. Mancebo et al. Políticas e gestão da educação superior: Transformações recentes e debates atuais (pp. 191-204). São Paulo: Xamã; Goiânia: alternativa.

Maués, O. C., \& Souza, M. B. (2016). Precarização do trabalho do docente da educação superior e os impactos na formação. Em Aberto, Brasília, 29(97), 73-85, set./dez.

Miranda, K. (2005). O trabalho docente na acumulação flexível. XXVIII Reunião da Anped, 2005, Caxambu: 40 anos de Pós-graduação em Educação no Brasil.

Oliveira, D. A. (2005). Regulação das políticas educacionais na América Latina e suas consequências para os trabalhadores docentes. Educação e sociedade, Campinas, 26(92), 753-775, Especial - Out.

Santos, S. D. (2012). A precarização do trabalho docente no Ensino Superior: dos impasses às possibilidades de mudanças. Educar em Revista. Curitiba, (46), 229-244, out./dez.

Tello, C. (2011). Perspectivas discursivas sobre profissionalização docente na América Latina. In: D. Oliveira, M. E. Pini \& M. Feldfeber (Orgs.). Politicas educacionais e trabalho docente: Perspectiva comparada (pp. 147-170). Belo Horizonte: Fino Traço.

Walker, V. S. (2016). El trabajo docente en la universidad: Condiciones, dimensiones y tensiones. Perfiles Educativos , IISUE-UNAM, 38(153), 105-119. 


\title{
Sobre o Autores
}

\section{Altair Alberto Fávero}

Universidade de Passo Fundo

altairfavero@gmail.com

ORCID: http:/ / orcid.org/0000-0002-9187-7283

Pós-Doutor (Bolsista Capes) pela Universidad Autónoma del Estado de México (UAEMéx), Doutor em Educação (UFRGS). Mestre em Filosofia do Conhecimento (PUC/RS), Especialista em Epistemologia das Ciências Sociais (UPF) e Graduado em Filosofia (UPF). Atua como professor e pesquisador no Curso de Filosofia, no Mestrado e Doutorado em Educação da UPF, onde coordena o projeto de Pesquisa Interdisciplinaridade, Docência Universitária e políticas (em andamento desde março de 2012).

\section{Diego Bechi}

Universidade de Passo Fundo

diego_bechi@yahoo.com.br

ORCID: http:/ / orcid.org/0000-0003-3476-4757

Doutor em Educação no Programa de Pós-Graduação da Universidade de Passo Fundo (UPF). Possui Graduação em Filosofia (2007), especialização em Metodologia para o Ensino de Filosofia (2009) e Mestrado em Educação (bolsista Capes) pelo PPGEdu da Universidade de Passo Fundo na linha de Políticas Educacionais. Atualmente participa do Grupo de Estudos e Pesquisas sobre Educação Superior (Gepes/UPF), coordenado pelo professor Dr. Altair Alberto Fávero, ligado ao PPGEdu/UPF.

\section{Sobre as Editoras Convidas}

\author{
Deise Mancebo \\ Universidade do Estado do Rio de Janeiro \\ deise.mancebo@gmail.com \\ http://orcid.org/0000-0001-8312-4495 \\ Doutora em Educação pela Pontifícia Universidade Católica de São Paulo. Professora Titular da \\ Universidade do Estado do Rio de Janeiro. Pesquisadora e professora do Programa de Pós- \\ graduação em Políticas Públicas e Formação Humana. Coordenadora da Rede Universitas/Br.
}

\section{Kátia Maria Teixeira Santorum}

Universidade do Estado do Rio de Janeiro

katia.santorum@gmail.com

https://orcid.org/0000-0003-2830-157X

Doutora em Saúde Pública pela Escola Nacional de Saúde Pública Sérgio Arouca / Fundação

Oswaldo Cruz (Fiocruz). Professora Adjunta da Universidade do Estado do Rio de

Janeiro. Pesquisadora e professora do Programa de Pós-graduação em Políticas Públicas e Formação Humana.

\section{Carla Vaz dos Santos Ribeiro}

Universidade Federal do Maranhão

carlavazufma@gmail.com

http://orcid.org/0000-0002-5518-9619 
Doutora em Psicologia Social pela Universidade do Estado do Rio de Janeiro. Professora Associada da Universidade Federal do Maranhão. Pesquisadora e professora do Programa de Pós-graduação em Psicologia da UFMA. Integrante da Rede Universitas/Br.

\section{Denise Bessa Léda}

Universidade Federal do Maranhão

denise.bessa.leda@gmail.com

http://orcid.org/0000-0002-8696-6126

Doutora em Psicologia Social pela Universidade do Estado do Rio de Janeiro. Professora da Universidade Federal do Maranhão. Professora permanente e pesquisadora do Programa de PósGraduação em Psicologia da Universidade Federal do Maranhão. Membro da Rede Universitas/Br e do Grupo de Pesquisa Psicodinâmica e Clínica do Trabalho da Associação Nacional de Pesquisa e Pós-graduação em Psicologia.

\section{Dossiê Especial \\ O Trabalho no Ensino Superior \\ arquivos analíticos de políticas educativas}

Volume 28 Número 13
20 de janeiro 2020
ISSN 1068-2341

\section{(c) (1) ()}

Los/as lectores/as pueden copiar, mostrar, distribuir, y adaptar este articulo, siempre y cuando se de crédito y atribución al autor/es y a Archivos Analíticos de Políticas Educativas, los cambios se identifican y la misma licencia se aplica al trabajo derivada. Más detalles de la licencia de Creative Commons se encuentran en https://creativecommons.org/licenses/by-

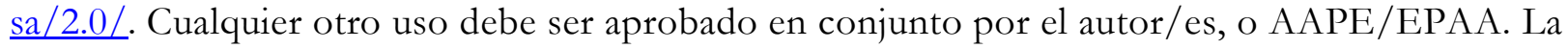
sección en español para Sud América de AAPE/EPAA es publicada por el Mary Lou Fulton Teachers College, Arizona State University y la Universidad de San Andrés de Argentina. Los artículos que aparecen en AAPE son indexados en CIRC (Clasificación Integrada de Revistas Científicas, España) DIALNET (España), Directory of Open Access Journals, EBSCO Education Research Complete, ERIC, Education Full Text (H.W. Wilson), PubMed, QUALIS A1 (Brazil), Redalyc, SCImago Journal Rank, SCOPUS, SOCOLAR (China).

Por errores y sugerencias contacte a Fischman@asu.edu

Síganos en EPAA's Facebook comunidad at https://www.facebook.com/EPAAAAPE y en Twitter feed@epaa_aape. 


\section{arquivos analíticos de políticas educativas conselho editorial}

Editor Consultor: Gustavo E. Fischman (Arizona State University)

Editoras Associadas: Andréa Barbosa Gouveia (Universidade Federal do Paraná), Kaizo Iwakami Beltrao, (Brazilian School of Public and Private Management - EBAPE/FGVl), Sheizi Calheira de Freitas (Federal University of Bahia), Maria Margarida Machado, (Federal University of Goiás / Universidade Federal de Goiás), Gilberto José Miranda, (Universidade Federal de Uberlândia, Brazil), Marcia Pletsch, Sandra Regina Sales (Universidade Federal Rural do Rio de Janeiro)

\author{
Almerindo Afonso \\ Universidade do Minho \\ Portugal
}

Rosanna Maria Barros Sá

Universidade do Algarve

Portugal

\section{Maria Helena Bonilla \\ Universidade Federal da Bahia \\ Brasil}

Rosa Maria Bueno Fischer Universidade Federal do Rio

Grande do Sul, Brasil

Alice Casimiro Lopes

Universidade do Estado do Rio de

Janeiro, Brasil

\section{Suzana Feldens Schwertner Centro Universitário Univates Brasil}

Geovana Mendonça Lunardi Mendes Universidade do Estado de Santa Catarina

Flávia Miller Naethe Motta

Universidade Federal Rural do Rio de Janeiro, Brasil

Alexandre Fernandez Vaz

Universidade Federal de Santa

Catarina, Brasil

Regina Célia Linhares Hostins

Universidade do Vale do Itajaí,

Brasil

\section{Alfredo Macedo Gomes \\ Universidade Federal de \\ Pernambuco Brasil}

Jefferson Mainardes

Universidade Estadual de Ponta

Grossa, Brasil

Jader Janer Moreira Lopes

Universidade Federal Fluminense

e Universidade Federal de Juiz de Fora, Brasil

\section{Debora Nunes \\ Universidade Federal do Rio \\ Grande do Norte, Brasil}

Alda Junqueira Marin Pontifícia Universidade Católica de São Paulo, Brasil

Dalila Andrade Oliveira

Universidade Federal de Minas Gerais, Brasil
José Augusto Pacheco

Universidade do Minho, Portugal

Jane Paiva

Universidade do Estado do Rio de Janeiro, Brasil

Paulo Alberto Santos Vieira Universidade do Estado de Mato Grosso, Brasil

Fabiany de Cássia Tavares Silva Universidade Federal do Mato Grosso do Sul, Brasil

\section{António Teodoro}

Universidade Lusófona

Portugal

\section{Lílian do Valle}

Universidade do Estado do Rio de Janeiro, Brasil

\author{
Alfredo Veiga-Neto \\ Universidade Federal do Rio \\ Grande do Sul, Brasil
}




\section{archivos analíticos de políticas educativas consejo editorial}

Editor Consultor: Gustavo E. Fischman (Arizona State University)

Editores Asociados: Felicitas Acosta (Universidad Nacional de General Sarmiento, Argentina), Armando Alcántara Santuario (Universidad Nacional Autónoma de México), Ignacio Barrenechea, Jason Beech (Universidad de San Andrés), Angelica Buendia, (Metropolitan Autonomous University), Alejandra Falabella (Universidad Alberto Hurtado, Chile), Carolina Guzmán-Valenzuela (University of Chile), Veronica Gottau (Universidad Torcuato Di Tella), Antonio Luzon, (Universidad de Granada), José Luis Ramírez, (Universidad de Sonora), Paula Razquin, Axel Rivas (Universidad de San Andrés), Maria Veronica Santelices (Pontificia Universidad Católica de Chile), Maria Alejandra Tejada-Gómez (Pontificia Universidad Javeriana, Colombia)

Claudio Almonacid

Universidad Metropolitana de

Ciencias de la Educación, Chile

\section{Miguel Ángel Arias Ortega}

Universidad Autónoma de la

Ciudad de México

Xavier Besalú Costa

Universitat de Girona, España

Xavier Bonal Sarro Universidad

Autónoma de Barcelona, España

Antonio Bolívar Boitia

Universidad de Granada, España

José Joaquín Brunner Universidad Diego Portales, Chile

Damián Canales Sánchez

Instituto Nacional para la

Evaluación de la Educación, México

Gabriela de la Cruz Flores

Universidad Nacional Autónoma de México

Marco Antonio Delgado Fuentes

Universidad Iberoamericana, México

Inés Dussel, DIE-CINVESTAV, México

Pedro Flores Crespo Universidad Iberoamericana, México
Ana María García de Fanelli

Centro de Estudios de Estado y

Sociedad (CEDES) CONICET,

Argentina

Juan Carlos González Faraco

Universidad de Huelva, España

María Clemente Linuesa

Universidad de Salamanca, España

Jaume Martínez Bonafé

Universitat de València, España

\section{Alejandro Márquez Jiménez}

Instituto de Investigaciones sobre la Universidad y la Educación, UNAM, México

María Guadalupe Olivier Tellez, Universidad Pedagógica Nacional, México

Miguel Pereyra Universidad de

Granada, España

Mónica Pini Universidad Nacional de San Martín, Argentina

Omar Orlando Pulido Chaves

Instituto para la Investigación

Educativa y el Desarrollo Pedagógico (IDEP)

José Ignacio Rivas Flores

Universidad de Málaga, España
Miriam Rodríguez Vargas

Universidad Autónoma de

Tamaulipas, México

José Gregorio Rodríguez

Universidad Nacional de Colombia, Colombia

Mario Rueda Beltrán Instituto de Investigaciones sobre la Universidad y la Educación, UNAM, México José Luis San Fabián Maroto Universidad de Oviedo, España

Jurjo Torres Santomé, Universidad de la Coruña, España

Yengny Marisol Silva Laya

Universidad Iberoamericana, México

Ernesto Treviño Ronzón

Universidad Veracruzana, México

Ernesto Treviño Villarreal

Universidad Diego Portales Santiago, Chile

Antoni Verger Planells Universidad Autónoma de Barcelona, España

Catalina Wainerman

Universidad de San Andrés, Argentina

Juan Carlos Yáñez Velazco

Universidad de Colima, México 


\section{education policy analysis archives editorial board}

Lead Editor: Audrey Amrein-Beardsley

Editor Consultor: Gustavo E. Fischman (Arizona State University)

Associate Editors: Melanie Bertrand, David Carlson, Lauren Harris, Eugene Judson, Mirka Koro-Ljungberg, Daniel Liou, Scott Marley, Molly Ott, Iveta Silova (Arizona State University)

Cristina Alfaro

San Diego State University

Gary Anderson

New York University

Michael W. Apple

University of Wisconsin, Madison

Jeff Bale

University of Toronto, Canada

Aaron Bevanot SUNY Albany

David C. Berliner

Arizona State University

Henry Braun Boston College

\section{Casey Cobb}

University of Connecticut

Arnold Danzig

San Jose State University

Linda Darling-Hammond

Stanford University

Elizabeth H. DeBray

University of Georgia

David E. DeMatthews

University of Texas at Austin

Chad d'Entremont Rennie Center

for Education Research \& Policy

John Diamond

University of Wisconsin, Madison

Matthew Di Carlo

Albert Shanker Institute

Sherman Dorn

Arizona State University

Michael J. Dumas

University of California, Berkeley

Kathy Escamilla

University ofColorado, Boulder

Yariv Feniger Ben-Gurion

University of the Negev

Melissa Lynn Freeman

Adams State College

Rachael Gabriel

University of Connecticut
Amy Garrett Dikkers University

of North Carolina, Wilmington

Gene V Glass

Arizona State University

Ronald Glass University of

California, Santa Cruz

Jacob P. K. Gross

University of Louisville

Eric M. Haas WestEd

Julian Vasquez Heilig California

State University, Sacramento

Kimberly Kappler Hewitt

University of North Carolina

Greensboro

Aimee Howley Ohio University

Steve Klees University of Maryland

Jaekyung Lee SUNY Buffalo

Jessica Nina Lester

Indiana University

Amanda E. Lewis University of

Illinois, Chicago

Chad R. Lochmiller Indiana

University

Christopher Lubienski Indiana

University

Sarah Lubienski Indiana University

William J. Mathis

University of Colorado, Boulder

Michele S. Moses

University of Colorado, Boulder

Julianne Moss

Deakin University, Australia

Sharon Nichols

University of Texas, San Antonio

Eric Parsons

University of Missouri-Columbia

Amanda U. Potterton

University of Kentucky

Susan L. Robertson

Bristol University
Gloria M. Rodriguez

University of California, Davis

R. Anthony Rolle

University of Houston

A. G. Rud

Washington State University

Patricia Sánchez University of

University of Texas, San Antonio

Janelle Scott University of

California, Berkeley

Jack Schneider University of

Massachusetts Lowell

Noah Sobe Loyola University

Nelly P. Stromquist

University of Maryland

Benjamin Superfine

University of Illinois, Chicago

Adai Tefera

Virginia Commonwealth University

A. Chris Torres

Michigan State University

Tina Trujillo

University of California, Berkeley

Federico R. Waitoller

University of Illinois, Chicago

Larisa Warhol

University of Connecticut

John Weathers University of

Colorado, Colorado Springs

Kevin Welner

University of Colorado, Boulder

Terrence G. Wiley

Center for Applied Linguistics

John Willinsky

Stanford University

Jennifer R. Wolgemuth

University of South Florida

Kyo Yamashiro

Claremont Graduate University

Miri Yemini

Tel Aviv University, Israel 